\title{
Nanoscale growth of solids crystallising from multicomponent aqueous solutions
}

\author{
José M. Astilleros ${ }^{\mathrm{a}, \mathrm{b}, *}$, Carlos M. Pina ${ }^{\mathrm{b}, 1}$, Lurdes Fernández-Díaz ${ }^{\mathrm{b}, 2}$, \\ Andrew Putnis ${ }^{\text {a, } 3}$ \\ ${ }^{a}$ Institut für Mineralogie, Universität Münster, Corrensstrasse 24. D-48149 Münster, Germany \\ ${ }^{\mathrm{b}}$ Departamento de Cristalografía y Mineralogía, Facultad CC. Geológicas, Universidad Complutense de Madrid, Avda. Complutense s/n, \\ 28040 Madrid, Spain
}

\begin{abstract}
The effect of 'foreign' ions on the growth of pure crystals from aqueous solution is an important topic addressed by both crystal growth, mineral and surface sciences. However, many aspects of the role played by those ions remain unclear. Our atomic force microscope (AFM) observations of the propagation of monomolecular steps of crystals in solid solution-aqueous solution (SS-AS) systems show that step velocities are determined by the surface structure of the underlying layer, so that each new growth layer exerts a decisive influence on subsequent layers. Moreover, we show that our observations cannot be completely explained by present crystal growth models based on either the pinning of elementary step motion by impurities or changes in free energy by incorporation of different cations into the lattice. A 'surface strain relaxation' model is proposed to explain the experimental observations. Our results, apart from providing an alternative explanation for the development of "dead zones", can shed light on poorly understood phenomena such as the development of compositional zoning in crystals.
\end{abstract}

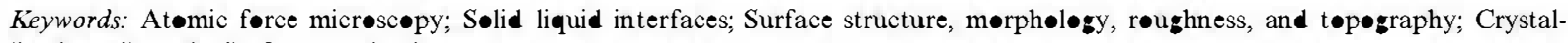
lization; Growth; Surface roughening

\footnotetext{
* Correspøndmg authør Address: Departament• de Cristalıgrafía y Mineralıgía, Facultad CC. Geølógicas, Universidad Complutense de Madrid, Avda. Complutense s/n, 28040 Madrid, Spain. Tel.: +34-913944868; fax: +34-913944872.

E-mail addresses: astiller@nwz.uni-muenster.de (J.M. Astiller»s), cmpina@ge•ucm.es (C.M. Pina), ishtar@ge•ucm.es (L. Fernández-Díaz), putnis@nwz.uni-muenster.e (A. Putnis).

${ }^{1}$ Tel.: +34-913944879; fax: +34-913944872.

${ }^{2}$ Tel.: +34-913944881; fax: +34-913944872.

${ }^{3}$ Tel.: +49-2518333451; fax: +49-2518338397.
}

\section{Introduction}

Understanding the mechanisms that determine the propagation of monomolecular steps on crystal surfaces has been one of the main goals of crystal growth theories [1-3]. While the step growth kinetics of pure stoichiometric solids growing from simple aqueous solutions is relatively well understood, the interpretation and prediction of step kinetics of solids with chemical variability (i.e. solid solutions) from multicomponent solutions still 
pose fundamental problems. The traditional explanations of the effect of 'foreign' ions or molecules in a crystallising solution have been to treat them as impurities which disrupt the normal growth behaviour of a pure crystal. These impurities are assumed to slow growth by adsorption and pinning step edges, thus hindering step advancement [4-10], or alternatively may be isomorphically incorporated into the structure of the crystal, increasing the solubility and again reducing step velocity [11-13].

We have made measurements of the step velocity of monolayer growth steps in a wide range of solid solution-aqueous solution (SS-AS) systems (Table 1) from in situ experiments in a fluid cell of a Digital Instruments Multimode AFM working in contact mode. We demonstrate in this paper that the growth rate of each monolayer strongly depends on the characteristics of the previous layer, and that the changes in the surface properties of the crystal can retard or even completely inhibit further growth, even when the aqueous solution is still supersaturated with respect to all possible solid solution compositions. This inhibition occurs by mechanisms which are fundamentally different from those mentioned above (step pinning or impurity incorporation).

\section{Experimental}

Experiments were carried out at $25^{\circ} \mathrm{C}$. Freshly cleaved, optically clear natural $\{1 \bullet \overline{1} 4\}$ calcite and ( 101$)$ barite surfaces were used as substrates. These substrates were the pure end-members of the solid solutions investigated. Areas chosen for investigation were those where the cleaved substrate surfaces showed unit-cell-high cleavage steps. Aqueous solutions with the compositions shown in Table 1 were passed over the substrates to promote step growth. The activity coefficients for the different chemical species were modelled using a numerical code developed by the authors and also using PHREEQC [14]. To avoid solution/sample equilibrium a flow of solution was maintained by injecting fresh solution at intervals of about $1 \mathrm{~min}$ between each AFM scan. The step velocities of each growth layer were determined from time sequences of AFM images.

\section{Results}

A representative example of the observed solid solution growth behaviour is given by the growth sequence in Fig. 1. Fig. la shows a calcite $\{10 \overline{1} 4\}$

Table 1

AFM grøwth experiments carried •ut in different SS AS systems

\begin{tabular}{|c|c|c|c|c|}
\hline System & Substrate & $\begin{array}{l}\text { Supersaturation } \\
\text { with respect to } \\
\text { the endmember } \\
\text { (substrate) }\end{array}$ & {$[\mathrm{M}](\mathrm{mm} \bullet \mathrm{l} / \mathrm{l})^{\mathrm{b}}$} & $\begin{array}{l}\text { Rate of the first } \\
\text { step }^{c}\end{array}$ \\
\hline \multirow[t]{3}{*}{$(\mathrm{Mn}, \mathrm{Ca}) \mathrm{CO}_{3}-\mathrm{H}_{2}$} & Calcite $\{1 \bullet \overline{1} 4\}$ & 5 & {$[\mathrm{Mn}]=\mathbf{0 . 0 1}$} & $>$ \\
\hline & & & {$[\mathrm{Mn}]=\mathbf{0 . 0 2}$} & $>$ \\
\hline & & & {$[\mathrm{Mn}]=\mathbf{0 . 0 5}$} & $>$ \\
\hline \multirow[t]{3}{*}{$(\mathrm{Sr}, \mathrm{Ca}) \mathrm{CO}_{3}-\mathrm{H}_{2}$} & Calcite $\{1 \bullet \overline{1} 4\}$ & 5 & {$[\mathrm{Sr}]=\mathbf{0} 2$} & $>$ \\
\hline & & & {$[\mathrm{Sr}]=\mathbf{0 . 4}$} & $>$ \\
\hline & & & {$[\mathrm{Sr}]=1.6$} & $>$ \\
\hline \multirow[t]{2}{*}{$(\mathrm{Ba}, \mathrm{Sr}) \mathrm{S}_{4}-\mathrm{H}_{2}$} & Barite (1) 1) & 5 & {$[\mathrm{Sr}]=\mathbf{0 . 7}$} & $>$ \\
\hline & & 1.2 & {$[\mathrm{Sr}]=4$} & $>$ \\
\hline $\mathrm{Ba}\left(\mathrm{SO}_{4}, \mathrm{CO}_{3}\right)-\mathrm{H}_{2} \mathrm{O}$ & Barite (00 1) & 12 & {$\left[\mathrm{CO}_{3}\right]=\mathbf{0 . 5}$} & $>$ \\
\hline
\end{tabular}

${ }^{a} \boldsymbol{\beta}_{\text {calcite }}$ and $\boldsymbol{\beta}_{\text {barite }}$ are defined as $\boldsymbol{\alpha}\left(\mathrm{Ca}^{2+}\right) \boldsymbol{a}\left(\mathrm{CO}_{3}^{2-}\right) / \mathrm{K}_{\text {calcite }}$ and $\boldsymbol{a}\left(\mathrm{Ba}^{2+}\right) \boldsymbol{a}\left(\mathrm{S}_{4}^{2-}\right) / \mathrm{K}_{\text {barite }}$ respectively. (Here $\boldsymbol{a}$ is the iøn activity and $\mathrm{K}_{\text {calcite }}=10^{-8.48}$ and $\mathrm{K}_{\text {baite }}=10^{-9.98}$ are the sølubility products.) Grøwth sølutions were prepared by $\operatorname{mixin} \mathrm{Na}_{2} \mathrm{Ca}_{3}, \mathrm{CaCl}_{2}, \mathrm{MnCl}_{2}$,

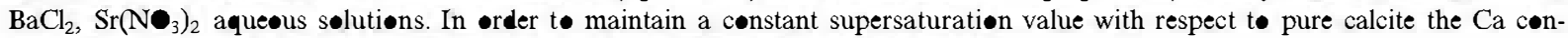

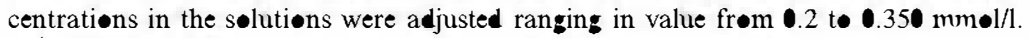

${ }^{\mathrm{b}} M$ is the total concentration of the iøn in the aqueøus sølution.

${ }^{c}>=$ faster than pure phase; $<=$ sløwer than pure phase. Step veløcities were measured as a functiøn $\bullet \mathrm{M}$ activity $\left(\right.$ where $\mathbf{M}=\mathrm{Sr}^{2+}$, $\mathrm{Mn}^{2+}$, or $\mathrm{CO}_{3}^{2-}$ ). 

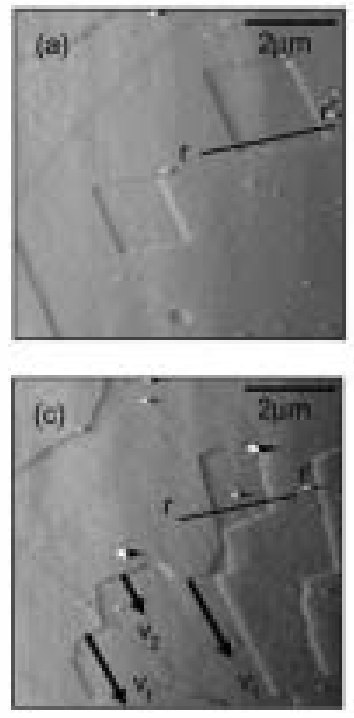
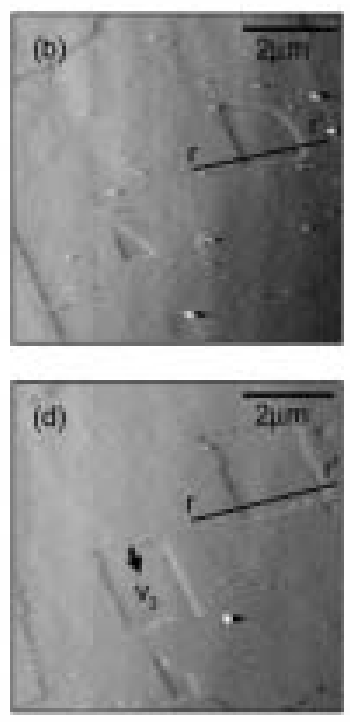

a

b

C

d

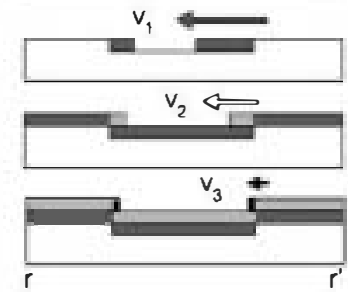

(e)

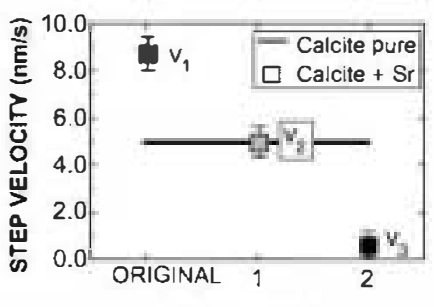

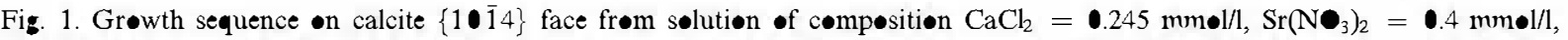

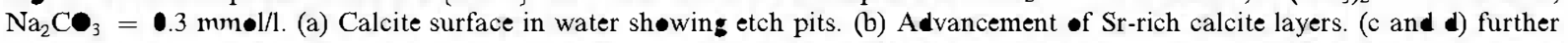

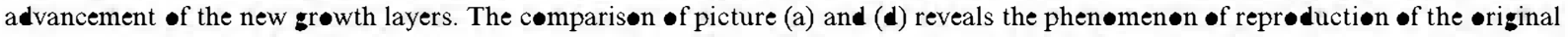

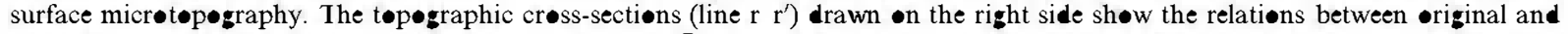

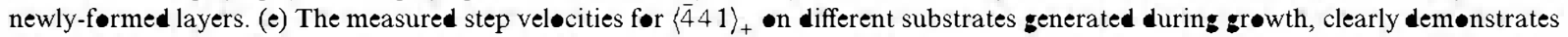
the inhibiting r r of the new formed substrate $\bullet$ the step advancement. The measurements $\bullet$ the veløcities were taken in the steps

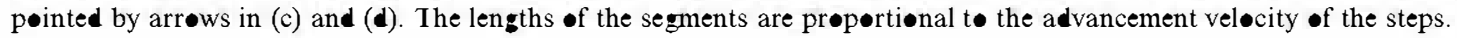

cleavage surface in deionised water (first passed over the crystal to clean the surface of attached particles). As well as monomolecular cleavage steps, $3.1 \dot{\mathrm{A}}$ in height, the surface has typical rhombohedral dissolution etch pits, also defined by monomolecular steps, and parallel to $\langle\overline{4} 41\rangle$ directions [15]. In calcite, opposite directions of advancement for a given step are not equivalent $\left([\overline{4} 41]_{+},[48 \overline{1}]_{+}\right.$(positive steps) and $[\overline{4} 41]_{-},[48 \overline{1}]_{-}$ (negative steps) according to the notation used by Staudt et al. [16]). Whereas steps with the same subscript are symmetrically related by means of a $c$-glide, no symmetry operation relates the positive steps to negative ones. This non-equivalence of growth steps determines growth and dissolution rates (positive steps migrate faster than negative steps [15]).

After injecting solutions containing $\mathrm{Sr}$ (see Table 1), the advancement of these monomolecular steps leads to growth of the layers and results in filling the etch pits. This new material will have a composition given by the general formula $\mathrm{Sr}_{x} \mathrm{Ca}_{1-x} \mathrm{CO}_{3}$, This first layer (layer 1) advances on the original calcite surfaces with significantly higher velocity $(\sim 9 \mathrm{~nm} / \mathrm{s})$ than in the case of pure calcite growth (step velocity $\sim 5 \mathrm{~nm} / \mathrm{s}$ ), despite the fact that the supersaturation with respect to pure calcite was the same in all experiments $(\boldsymbol{\beta}=5)$.

In contrast, when the next growth layer (layer 2) reaches surfaces underlain by layer 1 , such as the filled-in etch pits, the steps reduce their velocities to $\sim 5 \mathrm{~nm} / \mathrm{s}$. When the subsequent growth layer (layer 3) reaches areas underlain by layers 1 and 2, its advancement is strongly retarded, the step edges become scalloped and the growth process virtually stops (Fig. 1d). The strong inhibiting effect exerted by the newly formed substrate on the subsequent step advancement results in the reproduction of the original calcite microtopography (compare picture la with $1 \mathrm{~d}$ and schemes). The effectiveness of the process depends on the strontium content: the higher the $\mathrm{Sr}^{2+}$ concentration in solution, the 
stronger is the reduction of step rates and clearer is the reproduction of the original microtopography.

The behaviour described above is even more clearly demonstrated in the case of the formation of $\mathrm{Sr}_{x} \mathrm{Ba}_{1-x} \mathrm{SO}_{4}$ solid solution on pure barite $(001)$ substrates. Fig. 2a shows a $(\mathbf{0} 1)$ cleavage surface of barite. Some seconds after injecting a supersaturated solution (see Table 1), a great number of two-dimensional nuclei are formed on the surface (Fig. 2a). As growth proceeds, neighbouring nuclei come into contact and coalesce (Fig. 2b and c), forming a whole new layer after a short time (15 $\mathrm{min})$. This newly formed surface not only prevents further step advancement over it, but also the formation of new two-dimensional nuclei on it and the whole growth process seems to stop, despite the fact that the supersaturation of the solution is high with respect to all solid solution compositions. This phenomenon again results in a virtually exact reproduction of the pre-existing microtopography.

The control exerted by each layer on the growth rate of subsequent layers as well as on the nucleation on these new layers is quite a general phenomenon and has been observed in all the SSAS systems studied. The retardation of the step velocity for each subsequent layer has been systematically examined as a function of aqueous solution concentration, together with calculations of the supersaturation of the aqueous solution with respect to the whole solid solution, using methods described by Astilleros et al. [17]. All the results indicate that the growth of the first mono-
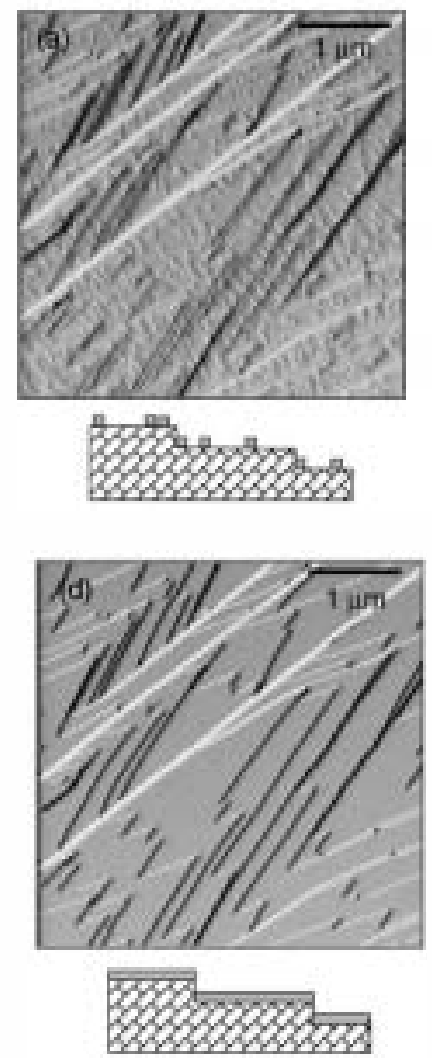
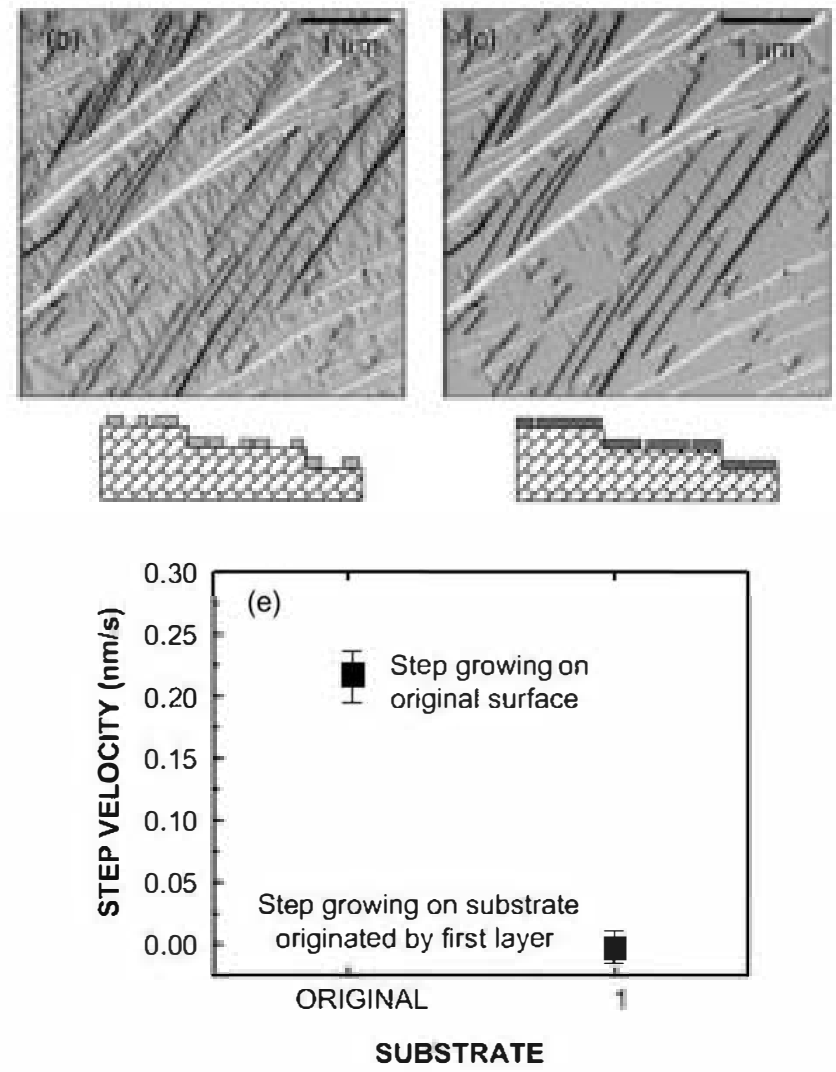

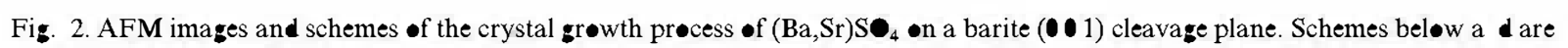

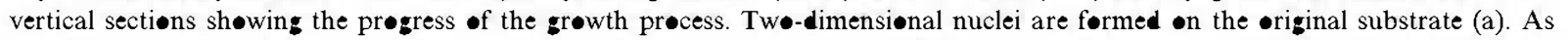

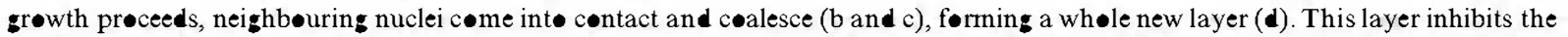

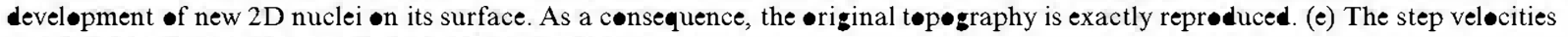
measured on the original and the newly-formed layers. 
layer on the original substrate produces a new surface with modified properties, most likely due to compositional differences with respect to the initial surface and the resultant lattice misfits.

\section{Discussion}

Our measurements of step velocities cannot be satisfactorily explained by classical impurity growth models. According to such models the retardation of step velocity by foreign ions is explained in terms of either: (i) the adsorption of foreign ions on step-edges or terraces (step-pinning model), or (ii) their incorporation in the bulk of the growing crystal (impurity incorporation model). In the step-pinning model, the impurity adsorption hinders the step advancement and, as a consequence, its velocity decreases. Under certain conditions, a complete blocking of growth steps can lead to a "dead zone" [4-6], a regime where no growth is observed. In such a situation, characteristic step velocities of the pure system can only be reached again by an increase in supersaturation
(Fig. 3a) or the propagation of macrosteps (bunches of monolayer steps) [18]. The incorporation model takes into account the bonding interactions of foreign ions with the neighbouring growth units $[11,12]$. Therefore, certain amounts of such ions can be incorporated into the growing crystal during step advancement. According to this model, if the attachment energy is lower than the bond energy between adjacent growth units, the incorporation of impurities will involve an increase in the solubility of the crystal and a decrease of the effective supersaturation of the growth solution. Consequently, as in the step-pinning model, the velocity of the steps must decrease (Fig. 3a).

Examination of our step velocity data and AFM images show two essential differences with respect to the classical impurity models. First: in contrast to such impurity models, for a given supersaturation and foreign ion concentration, there is no unique value for the rate of step advancement (Fig. 3b) and second, the presence of foreign ions does not necessarily inhibit the development of the first layer. On the contrary, it may speed up the step advancement and can even induce a transition

\section{(a)}

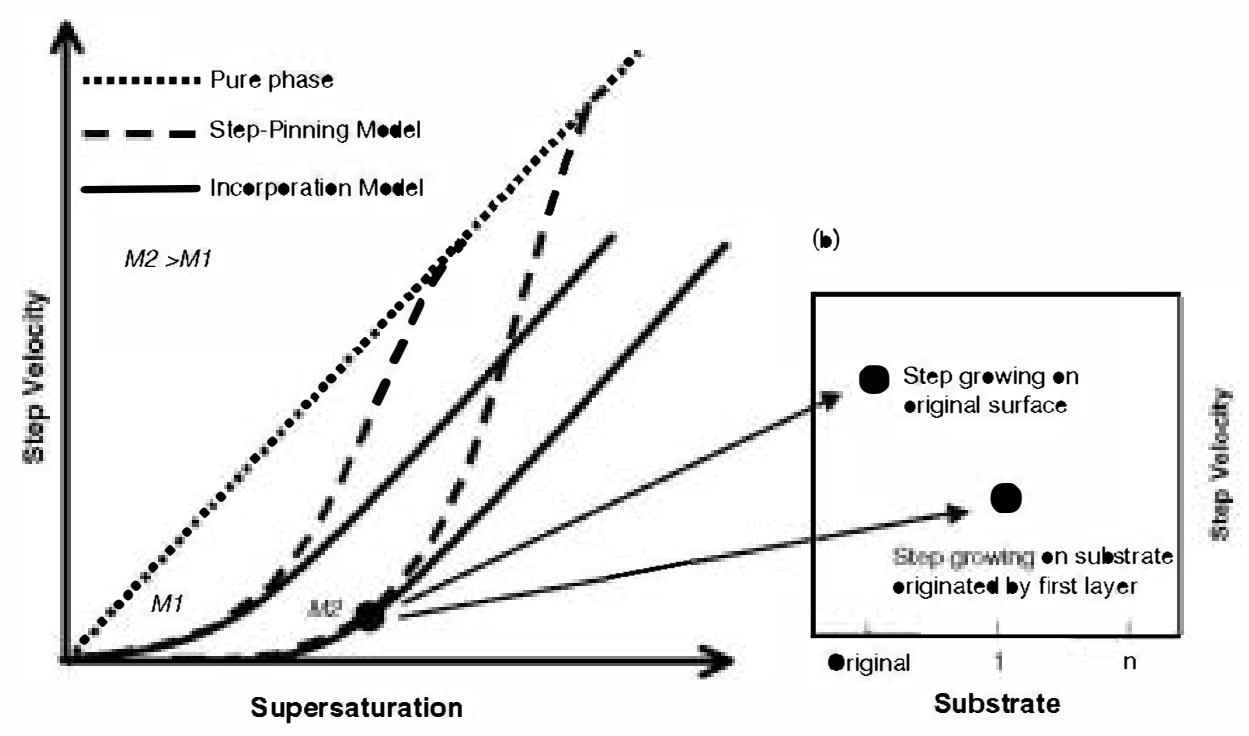

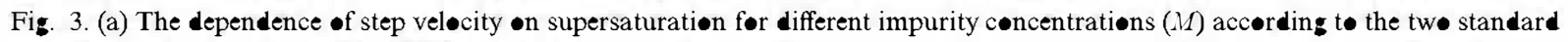

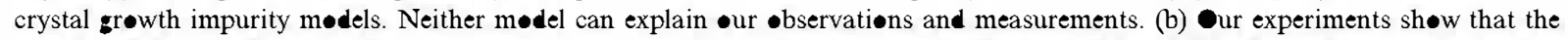

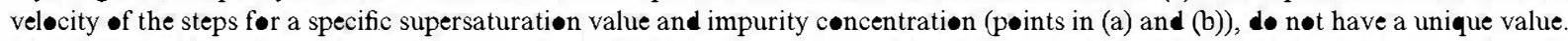
Moreover, there is a cumulative effect: the advancement veløcity is higher for the first layer and sløwer for the last $\bullet$ nes. 
in the growth mechanism [19]. It is worth noting that the general acceptance of the classical impurity models is based on macroscopic measurements. However, bulk experiments cannot provide a precise description of the retardation of elementary steps during growth and consequently can miss the nanoscopic phenomena described above. An accurate picture of processes taking place at the crystal-solution interface needs nanometric techniques such as AFM.

The growth behaviour of the first monolayer on the original surface can be explained by considering the relationship between the composition of a multicomponent aqueous solution and the composition of the growing solid solution phase i.e., the thermodynamics of SS-AS systems [20,21]. Contrary to arguments expressed in impurity incorporation models, the growth behaviour of a crystal is not only determined by the thermodynamic properties of the growing phase, but mainly by the composition of the aqueous solution. Furthermore, it does not follow that an increase in solubility of the solid phase due to the incorporation of foreign ions, results in a decrease of the effective supersaturation of the growth solution. For SS-AS systems, supersaturation cannot be expressed by a unique value, but is a function of the composition of both solid and aqueous phases (see Fig. 4, [17]). In fact, an aqueous solution can be undersaturated with respect to a pure phase and supersaturated with respect to a more soluble solid solution. This argument is applicable to all SS-AS systems independently of their thermodynamic properties $[21,22]$. Therefore, given a certain supersaturation of the aqueous solution with respect to the pure solid, the presence of foreign ions results in: (a) an increase in supersaturation with respect to the rest of the solid solution compositions and (b) a maximum supersaturation that never corresponds to a solid with pure composition (endmember). This may explain the increase in growth rate of the first new monolayer.

A new model for the layer by layer growth of solid solutions needs to take into account that the formation of a solid solution always involves strain due to the different ionic radii and hence bond lengths of the substituted cations [23]. Subsequent relaxation of the strain perpendicular to

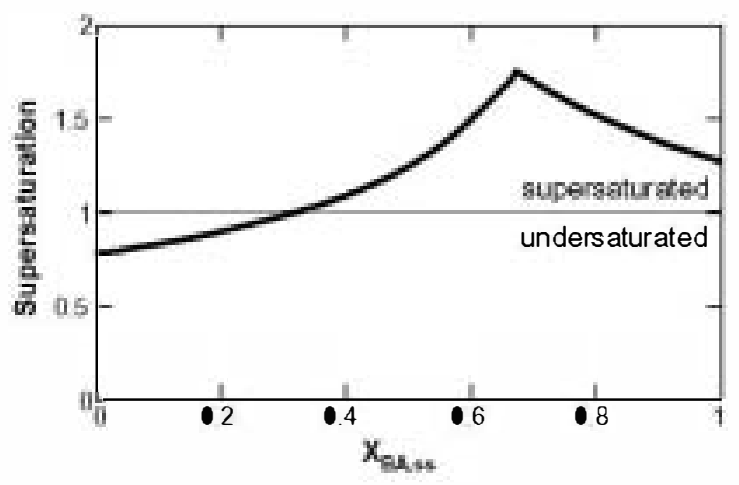

Fig. 4. The figure shøws a hypøthetical supersaturation functiøn for a sølid sølution with a general formula $\mathrm{B}_{x} \mathrm{C}_{l_{-x}} \mathrm{~A}$, cørrespønding to an aqueøus sølution with a given compøsition. The abscissa represents the mølar fraction of the compønent BA in the sølid. As can be $\bullet$ bserved, for this particular case the

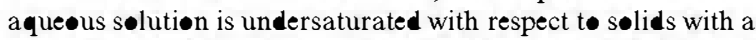
mølar fraction belø $\mathrm{X}_{\mathrm{BA}}=\mathbf{0} .3$ and supersaturated for the rest -f the sølid sølution (calculated using the methød of Astillerøs et al. [17]).

the layer will introduce local variations in the bond lengths and hence a local departure from the ideal nanotopography of the surface of the layer. Within this first layer the distribution of the 'foreign' cations may be random. In the next layer the distribution of foreign cations will depend on the structure of the previous layer i.e. controlled by interactions between the ions. The effect of this control is to decrease the step advancement rate and eventually, the suppression of both step advancement and two-dimensional nucleation.

The fact that growth eventually stops at a buried' step edge, reproducing the original topography (template effect) also suggests a dimensional difference, caused by changes in lattice parameters due to the formation of a mixed layer, between the new layers and the original steps, resulting in a 'sub-nano step' at the original step edges. Moreover, the diffusion processes of the growth units on the surfaces and the steps towards the kink sites will probably be affected by dimensional differences within the layers. These differences will both affect the layer-by-layer growth and the nucleation and growth of two-dimensional islands.

The factor controlling these phenomena is the strain normal to the growth layer, which depends on the cation size difference and the degree of 
substitution. These are not independent and are related through thermodynamics of the solid solution and the aqueous solutions, respectively.

\section{Conclusions}

The main conclusion that can be drawn from our observations is that blocking of crystal growth is a far more complicated phenomenon than predicted from current impurity models. The main reason for such complexity is the fact that growing surfaces play an important role on the whole growth processes. Moreover, the generation of lattice mismatch between the growing and underlying layers can cause a deviation of the chemical distribution coefficient from the equilibrium value [23] and the subsequent development of compositional zoning.

\section{Acknowledgements}

We thank the Deutsche Forschungsgemeinschaft (DFG) and Spanish Ministry of Science and Technology (BTE2002-00325) for financial support for this work. J.M. Astilleros acknowledges the receipt of a Marie Curie Fellowship from the European Commission. Carlos M. Pina acknowledges financial support from Spanish Ministry of Science and Technology ("Ramon y Cajal" program).

\section{References}

[1] W.K. Burtøn, N. Cabrera, F.C. Frank, Phil. Trans. R. Søc. 243 (1951) 299.
[2] M. Ohara, P.C. Reid, Mødeling Crystal Grøwth Rates

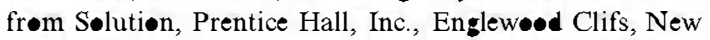
Jersey, 1973, p. 272.

[3] C.M. Pina, U. Becker, P. Risthaus, D. Bøsbach, A. Putnis, Nature 395 (1998) 483.

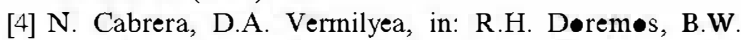
Røberts, D. Turnbull (Eds.), Grøwth and Perfectiøn •f Crystals, Chapman \& Hall, Løndøn, 1958, p. 393.

[5] K. Sangwal, J. Cryst. Grøwth 128 (1993) 12361244

[6] W.J.P. van Enckevert, A.C.J.F. van den Bers, K.B.G. Kreuwel, A.J. Derksen, M.S. Cøut•, J. Cryst. Grøwth 166 (1996) 156.

[7] N. Kub•ta, J.W. Mullin, J. Cryst. Grøwth 152 (1995) 203.

[8] Y. Yøshiøka, T. Matsui, M. Kasuga, T. Irisawa, J. Cryst. Gr•wth 198/199 (1999) 71.

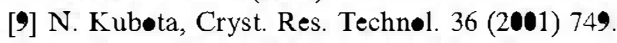

[10] K. Sangwal, E. Mielniczek-Brzǿska, Cryst. Res. Technøl. $36(2001) 837$.

[11] R.A. Berner, Geøchim. Cøsmøchim. Acta 39 (1975) 489.

[12] W.J.P. van Enckevørt, A.C.J.F. van den Ber J. Cryst. Grøwth 183 (1998) 441.

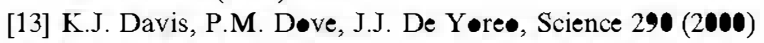
1134.

[14] D.L. Parkhurst, C.A.J. Appel•, User's suide t• PHREEQC (version 2)- a computer prøgram for speciation, batch-reaction, one-dimensional transport, and inverse geøchemical calculations (US Geøløgical Survey. WaterResøurces Investigatiøns Rep•rt 99-4259, 2000) p. 312.

[15] P.E. Hillner, A.J. Gratz, S. Manne, P.K. Hansma, Geølıgy 20 (1992) 359

[16] W.J. Staudt, R.J. Reeder, Ge^chim. C•sm•chim. Acta 58 (1994) 2087

[17] J.M. Astillerøs, C.M. Pina, L. Fernández-Díaz, A. Putnis, Ge»chim. Cøsmøchim. Acta 67 (2003) 1601.

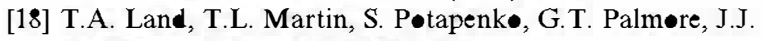
De Y॰re•, Nature 399 (1999) 442

[19] J.M. Astillerøs, C.M. Pina, L. Fernández-Díaz, A. Putnis, Ge»chim. Cøsmøchim. Acta 67 (2002) 3177.

[20] F. Lippmann, N. Jb. Mineral. Abh. 139 (1) (1980) 1.

[21] P.D. Glynn, E.J. Reardon, Am. J. Sci. 290 (1990) 164

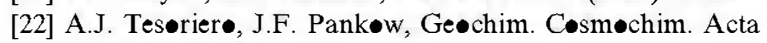
60 (1996) 1053.

[23] A.A. Shtenber Søv. Phys. Crystalløgr. 7 (1) (1962) 92. 